\title{
Push-out Bond Strength of Glass Fiber Posts with two Universal Adhesives in Endodontically-Treated Teeth
}

\author{
Azam Valian', Mahsa Maghsoudlou (D) 2, Mohammad Sajjad Roudbari ${ }^{3}$ \\ 1-Dept of Restorative dentistry, School of Dentistry, Shahid Beheshti University of medical Sciences \\ 2- Restorative Department, School of Dentistry, Shahid Beheshti University of Medical Sciences, Tehran, \\ Iran. \\ 3- Dept. of Restorative dentistry, School of Dentistry, Shahid Beheshti University of medical Sciences
}

\author{
Article History \\ Received:May 2021 \\ Accepted: Apr 2021 \\ ePublished: June 2021 \\ Corresponding author \\ M Maghsoudlou \\ Restorative Depart- \\ ment, School of \\ Dentistry, Shahid \\ Beheshti University \\ of Medical Sciences, \\ Tehran, Iran. \\ Email: maghsoudlou. \\ mahsa@gmail.com
}

\section{ABSTRACT}

Background and Aim: Attempts are ongoing to simplify the bonding procedure by decreasing the procedural steps. Universal adhesives were introduced to serve this purpose. This study aimed to evaluate the push-out bond strength of glass fiber posts in endodontically-treated teeth with two universal adhesives.

Materials and Methods: In this in vitro, experimental study, 22 single-rooted mandibular premolars were decoronated at their cementoenamel junction, endodontically treated and were randomly divided into two groups. The G-Premio Bond was used in the first and All-Bond Universal was used in the second group, according to the manufacturers' instructions. Angelus fiber posts were cemented using RelyX U200 Automix self-adhesive resin cement. The roots were cut into 1-mm-thick sections perpendicular to the longitudinal axis of the tooth in the cervical, middle, and apical thirds. The push-out test was performed in a universal testing machine at a crosshead speed of $1 \mathrm{~mm} / \mathrm{min}$, and bond strength values were recorded. The failure modes were also determined. The data were analyzed using ANOVA and linear mixed models $(\alpha=0.05)$.

Results: The mean push-out bond strength was significantly higher in All Bond Universal than $\mathrm{G}-$ Premio Bond $(\mathrm{P}=0.036)$. Also, there were statistically significant differences in the push-out bond strength of adhesives in different parts of the root canal $(\mathrm{P}=0.039)$. All failures were type 4 in both groups (adhesive failure between the dentin and resin cement).

Conclusion: All Bond Universal yielded superior push-out bond strength than GPremio. However, further in vitro and in vivo studies with larger sample size are required for an evidence-based decision making.

Keywords: Bond Sstrength; Endodontically Ttreated Tteeth; glass Fiber Pposts; Push-Oout Ttest; Universal Aadhesive

\section{J Res Dent Maxillofac Sci 2021;6(3):8-17.} Keywords: Uric Acid; Lactate Dehydrogenase; Amylase; Cigarette Smok-

\footnotetext{
Introduction

Restoration of endodontically-treated teeth is a challenging topic in operative dentistry. Endodontically-treated teeth that have lost a great portion of their structure often require post and core placement to provide retention for the coronal restoration. However, casting posts increase the risk of root fracture since they require post space preparation, undergo corrosion, exert wedging effect, and also have high modulus of elasticity. ${ }^{(1,2)}$ In the recent years, new types of
}

intracanal posts have beenwere introduced to the market and have gained increasing popularity due to favorable properties such as optimal mechanical properties, uniform stress distribution, requiring less tooth preparation, superior esthetics, and better light transmission to the apical region, which enhances cement polymerization in this area. ${ }^{(3)}$ A clinical study reported $94.3 \%$ survival rate for treatment of endodontically-treated teeth with fiber posts without root fracture.(4) Due to anatomical 
variations in dentin in different parts of the root, the quality of bonding of fiber posts to dentin often varies in the coronal, middle and apical thirds. The retention of fiber posts is influenced by a number of factors such as the bond strength between the post and resin cement, and the bond strength between the resin cement and root dentin. Some studies have shown absence of any porosity at the post-resin cement interface. In other words, dentin-resin cement interface is a weak interface in terms of bond strength. ${ }^{(5,6)}$

Universal adhesives are capable of bonding to different substrates and can be used in selfetch and total-etch modes. ${ }^{(7,8)}$ Considering the relatively recent introduction of universal adhesives to the dental market, information regarding their properties is still limited. Universal adhesives have undergone significant structural changes compared to with older generations of bonding agents, and have a complex chemical structure..$^{(9,10)}$ Universal adhesives are supplied in one bottle. They contain hydrophilic monomers and higher amount of solvent in order to better match the inherent moisture of dentin. ${ }^{(10,11)}$ However, presence of water, organic solvents, and acidic monomers in the composition of universal adhesives has created some concerns regarding their solubility in oral fluids and water sorption. ${ }^{(12,13)}$ Thus, their bonding durability ${ }^{(14)}$, structural stability, and mechanical properties ${ }^{(14)}$ in the long-term are still questionable.

Many studies have assessed the immediate bond strength of universal adhesives to tooth structure. ${ }^{(15)}$ However, durability and stability of the bond in the long-term is another important topic in need of further investigation. Universal adhesives have a $\mathrm{pH}$ of around 2.7, which is responsible for their self-etching capability. Such a low $\mathrm{pH}$ creates adequate acidity and a stable interface between the methacryloyloxydecyl dihydrogen phosphate (MDP) monomer and dentin or enamel.

Considering the gap of information on this topic, this study aimed to assess and compare the push-out bond strength of fiber posts to root dentin in use of two universal adhesives.

\section{Materials and Methods}

This in vitro, experimental study evaluated mandibular premolars extracted within the past 6 months as part of orthodontic treatment plan.
The study was approved in by the ethics committee of Shahid Beheshti University of Medical Sciences (IR.SBMU.RIDS.REC.1394.130). The sSample size was calculated to be 11 samples in each group according to a previous study by Ebrahimi et al, ${ }^{(16)}$ assuming 12-unit difference in bond strength between the two groups to be significant, standard deviation of 7.8, alpha $=0.05$, and beta $=0.05$ using PASS software.

The inclusion criteria were mandibular premolars with single-canal roots and adequate root length extracted within the past 6 months. The exclusion criteria were root fracture, cracks or root curvature, history of endodontic treatment, and short root length.

The teeth were immersed in $0.5 \%$ chloramine $\mathrm{T}$ solution for 24 hours $\mathrm{h}$ for disinfection. The teeth were then decoronated at the cementoenamel junction perpendicular to the longitudinal axis of the tooth using a disc with highspeed hand-piece under water spray. The root canals underwent root canal treatment $1 \mathrm{~mm}$ short of the root length $(15 \pm 1 \mathrm{~mm})$ with $\mathrm{RaCe}$ system. ${ }^{(1)}$ After each change of files, the root canals were rinsed with $3 \mathrm{~mL}$ of $2.5 \%$ sodium hypochlorite. ${ }^{(17)}$ Excess irrigating solution was suctioned out of the root canal, and the canals were dried with paper points. All root canals were filled with gutta-percha and AH-26 sealer using lateral compaction technique. The working length of the teeth was different due to their anatomical differences. After 24 hours h of storage in water at $37^{\circ} \mathrm{C}$, the coronal gutta-percha was removed from the root canals using \#2 and \#3 Gates-Glidden drills such that 4-5 $\mathrm{mm}$ of guttapercha remained in the apical region of the root canals. The post space in the canals was then prepared using \#1 and \#2 fiber post drills. ${ }^{(18)}$

The teeth were then randomly divided into two groups $(\mathrm{n}=11)$ and a translucent fiber post (Angelus) with a size matching the root canal diameter was selected for each root. Table 1 presents the information about the materials used in this study. All materials were used in accordance with the manufacturers' instructions. Table 2 shows the procedural steps in the two groups. Group 1. All Bond Universal $(\mathrm{pH}=3.2)$ : After rinsing the root canal, excess moisture was removed with paper points, and the canal was dried with air spray for 20 secondss. 
Table 1. Characteristics of the materials used in this study

\begin{tabular}{|c|c|c|c|}
\hline Material & Manufacturer & Type & Composition \\
\hline $\begin{array}{l}\text { Angelus } \\
\text { Fiber post }\end{array}$ & $\begin{array}{l}\text { Angelus, } \\
\text { Brazil }\end{array}$ & $\begin{array}{l}\text { Translucent } \\
\text { glass fiber post }\end{array}$ & $\begin{array}{l}\text { Triethyleneglycol } \\
\text { dimethacrylate21\%,urethane } \\
\text { dimethacrylate, highly } \\
\text { dispersible silicon dioxide, } \\
\text { ytterbium } \\
\text { trifluoride } 9 \% \text {,stabilizers and } \\
\text { catalysts } 0.5 \% \text {, glass fiber } 70 \%\end{array}$ \\
\hline $\begin{array}{l}\text { Bonding } \\
\text { agents }\end{array}$ & $\begin{array}{l}\text { Bisco, USA } \\
\text { GC, Japan }\end{array}$ & $\begin{array}{c}\text { All Bond } \\
\text { Universal } \\
\text { G-Premio Bond } \\
\text { GC }\end{array}$ & $\begin{array}{l}\text { 10-MDP Dimethacrylate resin, } \\
\text { HEMA, initiators, stabilizers, } \\
\text { water, } \\
\text { modified 10-MDP } \\
\text { Dimethacrylate resin, initiators, } \\
\text { stabilizers, water }\end{array}$ \\
\hline Rely X u200 & $\begin{array}{l}\text { 3M ESPE, } \\
\text { Germany }\end{array}$ & Resin cement & $\begin{array}{l}\text { Base paste (white): } \\
\text { Methacrylate monomers } \\
\text { containing phosphoric acid } \\
\text { groups, methacrylate monomers, } \\
\text { Silanated fillers, initiator } \\
\text { components, stabilizers } \\
\text { Catalyst paste (yellow): } \\
\text { Methacrylate monomers, } \\
\text { Alkaline (basic) fillers, Silanated } \\
\text { fillers, Initiator components, } \\
\text { Stabilizers, Pigments }\end{array}$ \\
\hline Etching gel & $\begin{array}{l}\text { Spident, } \\
\text { USA }\end{array}$ & Fine Etch 37 & Phosphoric acid 37\% \\
\hline
\end{tabular}

The bonding agent was applied to root dentin in two coats using a microbrush. Excess bonding agent was removed by paper points and it was thinned with air spray and light-cured for 20s using a light curing unit (Demetron LC, USA) with a light intensity of $650-700 \mathrm{~mW} / \mathrm{cm} 2 .{ }^{(19)}$ Group 2. G-Premio Bond (GC America) (pH of 1.5): Root canals were prepared as in group 1. The bonding agent was applied on dentin surface using a microbrush. Excess bonding agent was removed with paper points and it was thinned with air spray. Light curing was performed for 20 s using a light curing unit (Demetron LC, USA) with a light intensity of $650-700 \mathrm{~mW} / \mathrm{cm} 2$. $^{(20)}$

The intensity of the light curing unit was periodically checked by a radiometer (Kerr, USA).

Prior to cementation of the posts, the surface of glass fiber posts in all groups was etched with $37 \%$ phosphoric acid (Fine Etch, Spident) for 60 $\mathrm{s}$ and then rinsed with water and dried. It was then silanized (Monobond S, Ivoclar Vivadent) for 60 seconds s and completely air-dried. in both groups were cemented using Rely $\mathrm{X}$ U200 Automix self-adhesive resin cement (3M ESPE). ${ }^{(21)}$ The cement was delivered into the canal using an endo tip. The posts were then dipped in cement and placed in the canals. Light curing was performed from the top for $40 \mathrm{sec}-$ ondss. Prior to light curing, the teeth were covered in an aluminum wrap to prevent light from reaching the post through lateral root canal walls. The teeth were then mounted in acrylic resin, and $1 \mathrm{~mm}$ sections were made in three areas in the coronal, middle and apical regions (T201; Mecatome, Presi, Germany). The push-out bond strength was measured in by a universal testing machine (Z020; Zwick Roell GmbH Co., Ulm, Germany) at a crosshead speed of $0.5 \mathrm{~mm} / \mathrm{min}$. The load was applied from the apical region, and the push-out bond strength in megapascals (MPa) was measured by dividing the debonding force in Newtons to by the total bonding interface surface area in square-millimeters. The push-out bond strength was reported separately for the 
coronal, middle, and apical regions. The mode of failure was determined under a stereomicroscope (Olympus, Japan) and categorized into the following 5 groups. ${ }^{(22)}$

1.Adhesive failure between the post and resin cement (no cement remained on the post)

2.Mixed failure $(0-50 \%$ of cement remained on the post surface)

3.Mixed failure $(50-100 \%$ of cement remained on the post surface)

4.Adhesive failure between dentin and resin cement (the post was covered with resin cement)

5.Cohesive failure in dentin ${ }^{(22)}$ Data were analyzed using descriptive statistics, and the mean and standard deviation of push-out bond strength were reported. The Kolmogorov-Smirnov test and the Shapiro-Wilk test were used to assess the normal distribution of data. ANOVA and linear mixed models were also applied. $\mathrm{P}<0.05$ was considered statistically significant. All statistical analyses were carried out using SPSS version 20 (SPSS Inc., IL, USA).

\section{Results}

The Kolmogorov-Smirnov test and the Shapiro-Wilk test confirmed normal distribution of push-out bond strength data in different parts of the roots in both groups ( $\mathrm{P}>0.05)$. The mean bond strength was $9.9 \pm 4.67 \mathrm{MPa}$ in G-Premio Bond and 10.9 $\pm 4.44 \mathrm{MPa}$ in All Bond Universal group. Table 3 shows the mean bond strength in different parts of the root. As shown, the highest push-out bond strength was noted in the apical region, followed by the middle, and coronal regions, irrespective of the type of bonding agent. Comparison of the push-out bond strength in the three parts of the root revealed no significant difference in All Bond $(\mathrm{P}=0.195)$ or $\mathrm{G}-\mathrm{Bond}$ $(\mathrm{P}=0.06)$ groups. In All Bond group, the mean push-out bond strength in all three regions of the root was higher than the corresponding mean values in the G-Bond group.

Linear mixed models were applied in order to assess the difference in bond strength between the two groups in the three regions. This model accounted for the effects of group (G-Bond and All Bond), region of root (coronal, middle and apical), the interaction of the two, and number of levels on the results as well as the random effects of the sample. It showed that the mean push-out bond strength in All Bond Universal group was significantly higher than that in G-Bond group, irrespective of the part of $\operatorname{root}(\mathrm{P}=0.036)$.

Table 2. Procedural steps in the two groups

\begin{tabular}{|c|c|c|c|c|}
\hline Groups & $\begin{array}{l}\text { Bonding } \\
\text { agent }\end{array}$ & $\begin{array}{l}\text { Procedure } \\
\text { Resin agent }\end{array}$ & Resin Cement & Luting procedure \\
\hline Group 1 & All-bond & $\begin{array}{l}\text { Apply } 10 \mathrm{~s} \text {, } \\
\text { Remove } \\
\text { excess with } \\
\text { paper point, } \\
\text { Air dry } 20 \mathrm{~s} \text {, } \\
\text { Light } \\
\text { polymerize } 20 \\
\text { s. }\end{array}$ & $\begin{array}{l}\text { 3M ESPE } \\
\text { RelyX U200 } \\
\text { Automix Self- } \\
\text { Adhesive }\end{array}$ & $\begin{array}{l}\text { The post was silanized by } \\
\text { applying one layer of All } \\
\text { Bond for } 60 \mathrm{~s} \text { and then dried. } \\
\text { Mix base and catalyst for } 20 \\
\text { s, } \\
\text { Apply to root canal with Endo } \\
\text { Tips. } \\
\text { Remove excess resin with a } \\
\text { small brush, } \\
\text { Light polymerize for } 40 \mathrm{~s} \\
\text { through translucent fiber post. }\end{array}$ \\
\hline Group 2 & G-bond & $\begin{array}{l}\text { Apply } 10 \mathrm{~s} \text {, } \\
\text { Remove } \\
\text { excess with } \\
\text { paper point, } \\
\text { Air dry for } 20 \\
\text { s, } \\
\text { Light } \\
\text { polymerize } \\
\text { for } 20 \mathrm{~s} \text {. }\end{array}$ & $\begin{array}{l}\text { 3M ESPE } \\
\text { RelyX U200 } \\
\text { Automix Self- } \\
\text { Adhesive }\end{array}$ & $\begin{array}{l}\text { The post was silanized by } \\
\text { applying one layer of } \mathrm{G} \text { Bond } \\
\text { for } 60 \mathrm{~s} \text { and then dried. } \\
\text { Mix base and catalyst for } 20 \\
\mathrm{~s} \text {, } \\
\text { Apply to root canal with Endo } \\
\text { Tips. } \\
\text { Remove excess resin with a } \\
\text { small brush, } \\
\text { Light polymerize for } 40 \mathrm{~s} \\
\text { through translucent fiber post. }\end{array}$ \\
\hline
\end{tabular}

The difference in the mean push-out bond strength in the three areas of the root was also significant irrespective of the type of bonding agent used $(\mathrm{P}=0.039)$. The interaction effect of type of bonding agent and part of root on the push-out bond strength was not significant $(\mathrm{P}=0.26)$. Thus, the six mean values of push-out bond strength were not significantly different $(\mathrm{P}=0.26)$.

Table 3. Mean bond strength (MPa) in different parts of the root

\begin{tabular}{ccc}
\hline Group & Region & $\begin{array}{c}\text { Mean and std. } \\
\text { deviation (MPa) }\end{array}$ \\
\hline General & Coronal & $8.2 \pm 3.20$ \\
& Middle & $9 \pm 4.57$ \\
& Apical & $11.4 \pm 4.81$ \\
G-Bond & Coronal & $7.6 \pm 2.74$ \\
& Middle & $7.1 \pm 2.93$ \\
& Apical & $10.8 \pm 5.24$ \\
All Bond & Coronal & $8.9 \pm 3.60$ \\
& Middle & $11.8 \pm 4.81$ \\
& Apical & $12.0 \pm 4.51$ \\
\hline
\end{tabular}

Pairwise comparisons of the mean bond strength in the three areas revealed a significant difference in push-out bond strength of the coronal and apical regions $(\mathrm{P}=0.036)$.

Table 4 shows the frequency of different modes of failure in the two groups. As shown, all failures were type 4 in the coronal, mid- 
dle and apical thirds in both groups. Figures 1-8 illustrate the stereomicroscopic images of root cross-sections in three regions in the two groups at $\mathrm{x} 40$ magnification for qualitative assessment.

Table 4. Frequency of different modes of failure in the two groups

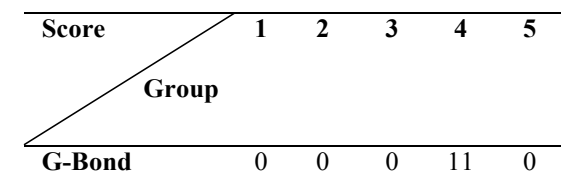

All-Bond $\quad \begin{array}{llllll}0 & 0 & 0 & 11 & 0\end{array}$

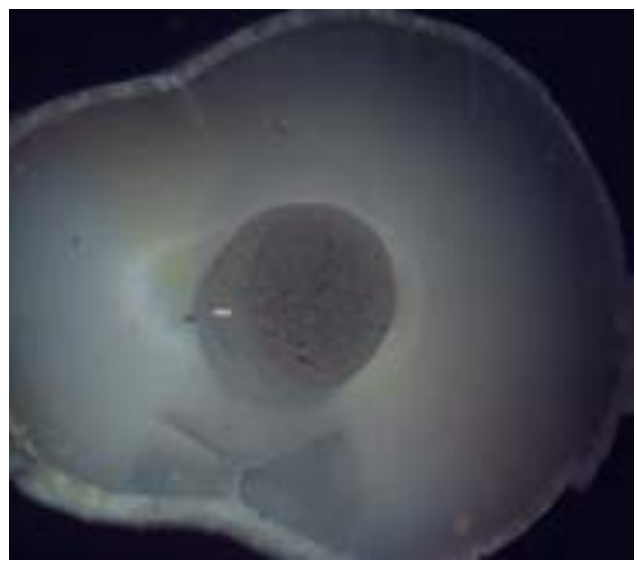

Figure 1. Stereomicroscopic image of the coronal view of the coronal third of a root and post space with type 4 failure mode

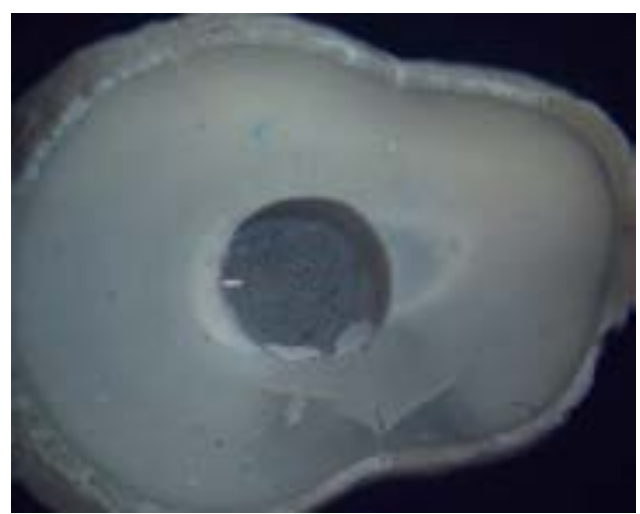

Figure 2. Stereomicroscopic image of the apical view of the coronal third of a root and post space

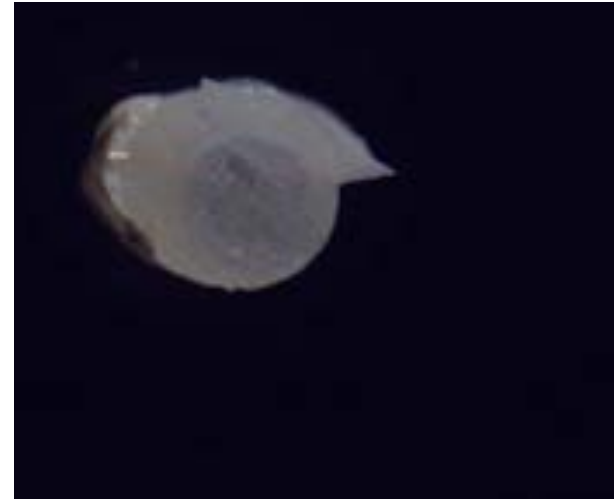

Figure 3. Stereomicroscopic image of a post segment with type 4 failure mode

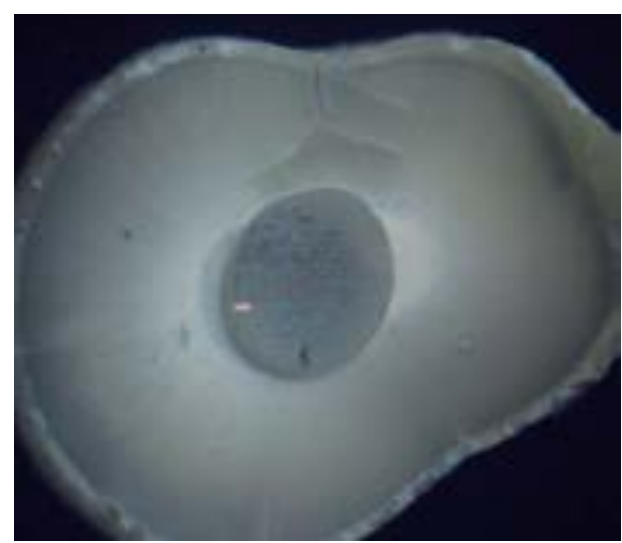

Figure 4. Stereomicroscopic image of the coronal view of the middle third of a root and post space with type 4 failure mode

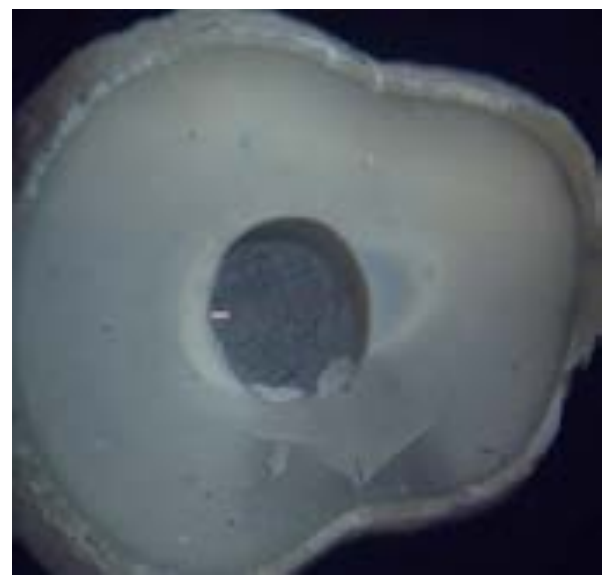

Figure 5. Stereomicroscopic image of the apical view of the middle third of a root and post space with type 4 failure mode 


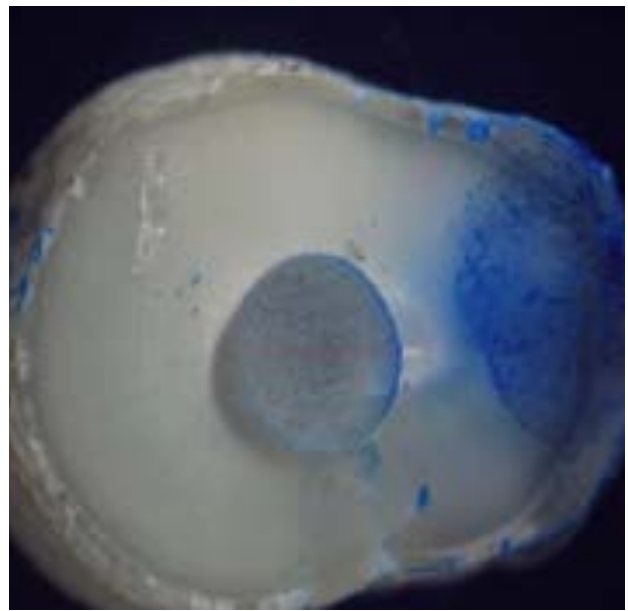

Figure 6. Stereomicroscopic image of the coronal view of the apical third of a root and post space with type 4 failure mode

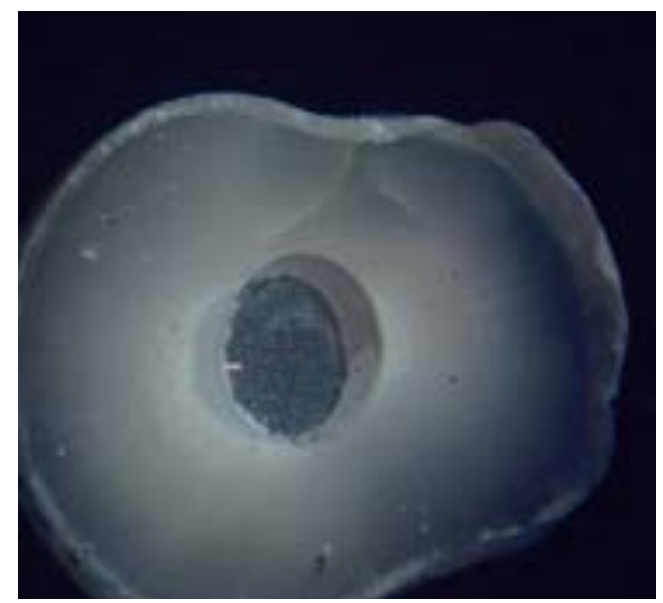

Figure 7. Stereomicroscopic image of the apical view of the apical third of a root and post space with type 4 failure mode

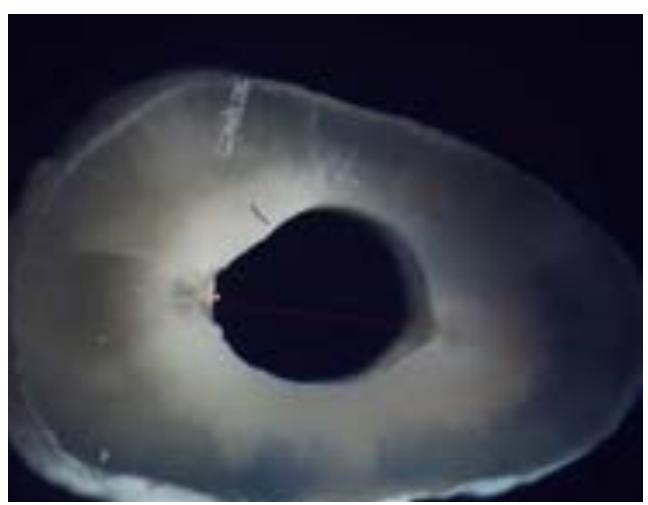

Figure 8. Stereomicroscopic image of a tooth segment and post space with type 4 failure mode

\section{Discussion}

This study evaluated the push-out strength of glass fiber posts with two different adhesives in endodontically-treated teeth. Several methods are available for assessment of bond strength of resin cement to root dentin such as microtensile, pull-out and push-out tests ${ }^{(23)}$ The push-out test applies shear load to the interface of cement and dentin and the post-cement interface, which is particularly important in the clinical setting. ${ }^{(24)}$ This test better assesses the bond strength than other tests because shear load is applied perpendicular to the bonding interface. ${ }^{(25)}$ Also, it is more reliable than microtensile test because premature failures commonly occur in microtensile test and distribution of load is also more limited in microtensile test. Thus, push-put test was performed in our study. Angelus Exacto fiber post was used in this study since Zicari et al. ${ }^{(26)}$ showed that this post as well as Dentin Post $\mathrm{X}$ have maximum light transmission among different fiber posts.

Our results showed that the mean push-out bond strength was significantly higher in All Bond Universal than G-Premio Bond group $(\mathrm{P}=0.036)$. Also, there were statistically significant differences in the push-out bond strength of adhesives in different parts of the root canal $(\mathrm{P}=0.039)$. These findings were in line with those of Potesta et al, ${ }^{(27)}$ and Grandini et al. ${ }^{(28)}$ They explained that the difference was due to incomplete washout of acid etchant in the apical part of the canal and inadequate moisture control, which decreased the bond strength in the apical third of the teeth bonded with two-step etch and rinse bonding agents. In contrast, our study showed lower bond strength in the coronal third, which may be due to the wider surface area in the coronal third and subsequently higher surface area for bonding; however, further investigations are required on this topic. Goracci et $\mathrm{al}^{(29)}$ and Valandro et al. ${ }^{(30)}$ reported contradictory results and showed that two-step etch and rinse bonding agents yielded higher bond strength than two-step self-etch bonding agents. They attributed this finding to inadequate removal of smear layer in use of selfetch bonding agents.

The bonding mechanism of adhesive systems to root dentin has a micromechanical nature, and is based on three parameters: (I) penetration 
of bonding agent into the demineralized dentin (formation of hybrid layer), (II) formation of resin tags, and (III) formation of lateral adhesive branches. ${ }^{(6,31)}$ Irrespective of presence of a significant difference, the results of these two studies indicated that the bond strength decreased from the coronal towards the apical region in all groups. One reason can be the decreased density and diameter of dentinal tubules from the coronal towards the apical region. This was also noted in scanning electron microscopic analyses by Bassem M Eid et al. ${ }^{(32)}$ on root dentin, who showed that the density of dentinal tubules in the coronal third was higher than that in the apical and middle thirds, and the diameter of dentinal tubules gradually decreased towards the apical region. The thickness of the hybrid layer also decreaseds from the coronal towards the apical and the lateral branches of dentinal tubules are were only seen in the middle and coronal thirds; this result was different from our finding. In another electron microscopic study, Ferrari et al. ${ }^{(33)}$ showed that the thickness of the hybrid layer and the number of resin tags in the coronal region were greater than those in the middle and apical thirds. Moroever, Grandini et al. ${ }^{(28)}$ revealed that the pressure of microbrush is minimum in the apical region, causing less penetration of adhesive into dentin. Gaston et al..$^{(34)}$ demonstrated that the number of dentinal tubules was lower in the apical region, and formation and morphology of resin tags in the cervical and middle parts of the roots were more uniform. Noirrit et al. ${ }^{(35)}$ evaluated the root dentin-bonding agent interface using a scanning electron microscope (SEM) and showed that the quality of resin tags in terms of length, density and number of lateral branches in the apical third was lower than that in the cervical and middle thirds. Nonetheless, controversial results in this respect call for further investigations.

Boing et al. ${ }^{(21)}$ discussed that fewer dentinal tubules in the apical region result in morphologically irregular dentin compared with the coronal cervical region. These dentinal tubules are highly sclerotic and full of minerals similar to the peritubular dentin that provides enough calcium for chemical bonding to self-adhesive RelyX U200 cement. Despite different results in use of the conventional resin cement, another interpretation for higher bond strength in the apical third is that these self-adhesive resin cements are 14J Res Dentomaxillofac Sci 2020;6(3) less susceptible to dentin moisture that is less controlled in the apical area. Similarly, Gaston

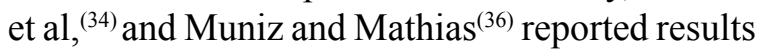
completely similar to ours. They reported that the bond strength in the apical region was higher than that in the coronal region. They offered a different explanation for their findings. They stated that the bond strength more depends on the solid dentin rather than the density of dentinal tubules. However, it should be noted that they performed microtensile test. They showed that during rotary instrumentation of the root canal system, smear layer is formed, which is better washed off in the cervical and middle regions compared with the apical third. However, higher bond strength in the apical third indicates that the bond strength more depends on internal factors such as dentin in the region rather than the presence/absence of smear layer. Pereira et $\mathrm{al}^{(37)}$ also revealed that the radicular dentin in the apical area presented higher bond strength compared with the middle and cervical regions. They mentioned that density of the tubules is not a determinant factor for self-adhesive resin cements. The same result was reported by Aksornmuanget al, ${ }^{(38)}$ who showed that a self-etch dual-cure bonding agent provided a stronger bond than a self-etch light-cure bonding agent in the apical region. Akgungor and Akkayan $^{(39)}$ and Foxton et al. ${ }^{(40)}$ reported different results and showed that the bond strength of light-cure bonding agents was higher than that of dual-cure bonding agents. A two-step self-etch bonding agent (Clearfil liner Bond 2V) was used in the aforementioned two studies. The authors explained that this bonding agent contains a photo-initiator and 10-MDP acidic phosphate monomer while dual-cure activator contains initiator and does not have 10MDP. When mixed, the concentration of photo-initiator and MDP decreases, which leads to a reduction in degree of polymerization and the ability to bond to root dentin in dual-cure bonding agents.

In our study, all failures were type 4 in both groups (adhesive failure between dentin and resin cement). No case of mixed failure was noted, which shows that this area is the weakest interface. D'Arcangelo et al. ${ }^{(41,42)}$ in their studies used FRC glass fiber posts, Endo Light Post and Postec Plus posts and observed that the majority of failures occurred between the cement and the post; their results were different from our findings.

http://www.jrdms.dentaliau.ac.ir 
However, Zicari et al. ${ }^{(26)}$ used Para Post Fiberlux posts and Kececi et al. ${ }^{(43)}$ used FRC Postec Plus glass fiber posts and DT Light Post quartz fiber posts and observed that the majority of failures occurred at the cement-dentin interface. Their findings were in line with our results, which can be due to the quality of bonding of the cement and post, and the level of porosity of the post surface in comparison with dentin. We used selfetch Rely X U200 resin cement for cementation of posts, which has an acidic pH.Many studies have evaluated the effect of $\mathrm{pH}$ of resin cement on bond strength. ${ }^{(44,45)}$ Franco et al. ${ }^{(45)}$ showed that Single Bond and Multipurpose Bond provided a low bond strength due to the low $\mathrm{pH}$ (2.1 and 4.6) of acidic monomers in their composition.

They added that use of acidic adhesives in combination with auto-polymerizing resin can significantly decrease the bond strength. Also, $\mathrm{pH}$ is important in bond strength of universal adhesives. All Bond Universal and G-Premio Bond have a pH of 3.2 and 1.5, respectively, and both cause incomplete demineralization of dentin surface. Apatite crystals remain around collagen fibers. ${ }^{(46)}$ The effect of $\mathrm{pH}$ is more prominent when the adhesive is usedin self-etch mode, which was adopted in our study. In general, it can be concluded that the bond strength of All Bond Universal is higher than other adhesives, which can be due to its better compatibility with dual-cure resin cements in environments with higher $\left.\mathrm{pH} .{ }^{(47}\right)$ In fact, creating a suitable surface to enhance micromechanical bonding depends on the $\mathrm{pH}$ of adhesive. A review study by da Rosa et al. ${ }^{(47)}$ indicated that acidic monomers can significantly affect the bond strength, and a mild self-etch adhesive with a $\mathrm{pH}$ of 2.5 to 3.1 is the best option for bonding to dentin. This $\mathrm{pH}$ is equal to the $\mathrm{pH}$ of All Bond Universal. ${ }^{(47)}$

Controversy between our results and those of previous studies may be attributed to our methodology and laboratory procedures of sectioning. For instance, we used conical posts, which may complicate sectioning and consequently affect the results. Also, we used self-etch bonding instead of total etch bonding and thus, there was no need for rinsing and etching. This could have also affected the results. This study had an in vitro design and generalization of results to the clinical setting should be done with caution. Future clinical studies are required to cast a final judgment in this respect. Also, future studies are recommended to use advanced imaging techniques to more accurately assess the quality of bonding interface.

\section{Conclusion}

Within the limitations of this study, the results showed that All Bond Universal can yield a higher push-out bond strength than G-Premio Bond for bonding of glass fiber posts in root canals of endodontically treated teeth in vitro.

\section{References}

1.Aflaki S, Boyerahmadi E, Talaei A, Safari MR, Mohammadpour M, Mohammadi N, et al.

In vitro transportation of curved canals following glide path preparation by Path File and Scout RaCe rotary systems versus manual instrumentation using cone-beam computed tomography. Front Dent 2020 Nov; 17:30.

2.Pang J, Feng C, Zhu X, Liu B, Deng T, Gao Y, et al. Fracture behaviors of maxillary central incisors with flared root canals restored with CAD/CAM integrated glass fiber postand-core. Dent Mater J. 2019 Jan;38(1):114-9.

3.Özcan M, Volpato CAM. Current perspectives on dental adhesion: (3) Adhesion tointraradicular dentin: Concepts and applications. Jpn Dent Sci Rev. 2020 Sep;(56).

4.Guldener KA, Lanzrein CL, Guldener BES, Lang NP, Ramseier CA, Salvi GE. Long-term Clinical Outcomes of Endodontically Treated Teeth Restored with or without Fiber Postretained Single-unit Restorations. J Endod. 2017 Feb;43(2):188-93.

5.Carvalho RF, Cardenas A, Carvalho CN, de Souza JJ, Bauer J, Siqueira F, et al. Effect of the Photo-initiator System Contained in Universal Adhesives on Radicular Dentin Bonding. Oper Dent. 2020 Sep;45(5):547-55.

6.Miotti LL, Follak AC, Montagner AF, Pozzobon RT, da Silveira BL, Susin AH. Is conventional resin cement adhesive performance to dentin better than self-adhesive? A systematic review and meta-analysis of laboratory studies. Oper Dent. 2020 Sep;45(5):484-95.

7.Perdigao J, Sezinando A, Monteiro P. Evaluation of a new universal adhesive using different bonding strategies. J Dent Res. 2012 Mar 21;91(Special issue A).

8. Mena-Serrano A, Kose C, De Paula EA, Tay LY, Reis $\mathrm{A}$, Loguercio $\mathrm{AD}$, et al. A new universal simplified adhesive: 6-month clinical evaluation. J EsthetRestor Dent. 2013 Feb;25(1):55-69.

9.Muñoz MA, Luque I, Hass V, Reis A, Loguercio $\mathrm{AD}$, Bombarda NH. Immediate bonding properties of universal adhesives to dentine. J Dent.2013 May;41(5):404-11. 10. Dhanpal PC, Yiu CK, King NM, Tay FR, Hiraishi N. Effect of temperature on water sorption and solubility of dental adhesive resins. J Dent. 2009 Feb 1;37(2):122-32.

11. Muñoz MA, Sezinando A, Luque-Martinez I, Szesz AL, Reis A, Loguercio AD, et al. Influence of a hydrophobic resin coating on the bonding efficacy of three universal adhesives. J Dent. 2014 May;42(5):595-602. 
12. Häfer M, Schneider H, Rupf S, Busch I, Fuchß A, Merte I, et al. Experimental and clinical evaluation of a self-etching and an etch-and-rinse adhesive system. J Adhes Dent. 2013

May;15(3):275-86.

13. De Munck JD, Van Landuyt K, Peumans M, Poitevin A, Lambrechts P, Braem M, et al. A critical review of the durability of adhesion to tooth tissue: methods and results. J Dent Res.2005 Feb;84(2):118-32.

14. McDonough WG, Antonucci JM, He J, Shimada Y, Chiang MY, Schumacher GE, et al. A microshear test to measure bond strengths of dentin-polymer interfaces. Biomaterials. 2002 Sep;23(17):3603-8.

15. Hardan L, Bourgi R, Kharouf N, Mancino D,Zarow M, Jakubowicz N, et al. Bond strength of universal adhesives to dentin: A systematic review and meta-analysis. Polymers. 2021;13(5).

16. Ebrahimi SF, Shadman N, Nasery EB, Sadeghian F. Effect of polymerization mode of two adhesive systems on push-out bond strength of fiber post to different regions of root canal dentin. Dent Res J. 2014 Jan;11(1):32.

17. Forghani M, Afshari E, Parisay I, Garajian R. Effect of a passive sonic irrigation system on elimination of Enterococcus faecalis from root canal systems of primary teeth, using different concentrations of sodium hypochlorite: An in vitro evaluation. J Dent Res Dent Clin Dent Prospect. 2017;11(3):177-82

18. Portigliatti RP, Tumini JL, Bertoldi Hepburn AD, Aromando RF, Olmos JL. Correspondence between fiber post and drill dimensions for post canal preparation. Am J Dent. 2017

Dec;30(6):295-8.

19. Shafiei F, Mohammadparast P, Jowkar Z. Adhesion performance of a universal adhesive in the root canal: Effect of etch-and-rinse vs. self-etch mode. PloS one. 2018 Apr;13(4):e0195367.

20. Poggio C, Beltrami R, Colombo M, Chiesa M, Scribante A. Influence of dentin pretreatment on bond strength of universal adhesives. ActaBiomater. Odontol. Scand. 2017 Jan;3(1):30-5.

21. Boing TF, Gomes GM, Gomes JC, Reis A, Gomes OM. Is the bonding of self-adhesive cement sensitive to root region and curing mode? Journal of applied oral science :revista FOB. 2017 Feb;25(1):2-9.

22. Durski MT, Metz MJ, Thompson JY, Mascarenhas AK, Crim GA, Vieira S, et al. Push-out bond strength evaluation of glass fiber posts with different resin cements and application techniques. Oper Dent. 2016 Jan;41(1):103-10.

23. Foxton RM, Nakajima M, Tagami J, Miura H. Adhesion to root canal dentine using one and two $\square$ step adhesives with dual $\square$ cure composite core materials. J Oral Rehabil. 2005 Feb;32(2):97-104.

24. Mallmann A, Jacques LB, Valandro LF, Mathias P, Muench A. Microtensile bond strength of light-and selfcured adhesive systems to intraradicular dentin using a translucent fiber post. Oper Dent. 2005 Jul;30(4):500-6. 25. Marchesi G, Frassetto A, Mazzoni A, Apolonio F, Diolosa M, Cadenaro M, et al. Adhesive performance of a multimode adhesive system: 1-year in vitro study. J Dent. 2014 May;42(5):603-12.
26. Zicari F, Couthino E, De Munck J, Poitevin A, Scotti R, Naert I, et al. Bonding effectiveness and sealing ability of fiber-post bonding. Dent Mater. 2008 Jul;24(7):967-77. 27. Potesta FL, Broome JC, O’Neal SJ, Givan DA, Ramp LC. The effect of etching technique on the retention of adhesively cemented prefabricated dowels. J Prosthodont. 2008 Aug;17(6):445-50.

28. Grandini S, Sapio S, Goracci C, Monticelli F, Ferrari M. A one step procedure for luting glass fibre posts: an SEM evaluation. IntEndod J. 2004 Oct;37(10):679-86.

29. Goracci C, Sadek FT, Fabianelli A, Tay FR, Ferrari M. Evaluation of the adhesion of fiber posts to intraradicular dentin. Oper Dent. 2005 Sep;30(5):627-35.

30. Valandro LF, Valera MC, de Araujo MA. The effect of adhesive systems on the pullout strength of a fiberglass-reinforced composite post system in bovine teeth. J Adhes Dent. 2005 Dec;7(4).

31. Sofan E, Sofan A, Palaia G, Tenore G, Romeo U, Migliau G. Classification review of dental adhesive systems: from the IV generation to the universal type. Annali di stomatologia. $2017 \mathrm{Jan} ; 8(1): 1-17$.

32. Eid BM, Waly AS, Princy P, Venkatesan R. scanning electron microscope Evaluation of dentinal tubules penetration of three different root Canal Sealers. EC Dent Sci. 2019;18:1121-7.

33. Ferrari M, Vichi A, Grandini S, Goracci C. Efficacy of a self-curing adhesive--resin cement system on luting glassfiber posts into root canals: An SEM investigation. Int J Prosthodont. 2001 Nov; 14(6).

34. Gaston BA, West LA, LiewehrFR, Fernandes C, Pashley DH. Evaluation of regional bond strength of resin cement to endodontic surfaces. J Endod. 2001 May;27(5):321-4.

35. Noirrit EE, Grégoire G, Cournot M. Morphological study of fiber-reinforced post- bonding system-root dentin interface by evaluation of two bonding systems. J Dent. 2008 Mar;36(3):204-13.

36. Muniz L, Mathias P. The influence of sodium hypochlorite and root canal sealers on post retention in different dentin regions. Oper Dent. 2005 Jul;30(4):533.

37. Pereira JR, Pamato S, Santini MF, Porto VC, Ricci WA, So MVcR. Push-out bond strength of fiberglass posts cemented with adhesive and self-adhesive resin cements according to the root canal surface. Saudi Dent J. 2019 Nov;33:22-6.

38. Aksornmuang J, Nakajima M, Foxton RM, Tagami J. Effect of prolonged photo-irradiation time of three self-etch systems on the bonding to root canal dentine. J Dent. 2006 Jul;34(6):389-97.

39. Akgungor G, Akkayan B. Influence of dentin bonding agents and polymerization modes on the bond strength between translucent fiber posts and three dentin regions within a post space. J. Prosthet. Dent. 2006 May;95(5):368-78.

40. Foxton RM, Nakajima M, Tagami J, Miura H. Bonding of photo and dual-cure adhesives to root canal dentin. Oper Dent. 2003 Sep;28(5):543-51.

41. D'Arcangelo C, D'Amario M, Vadini M, Zazzeroni S, De Angelis F, Caputi S. An evaluation of luting agent application technique effect on fibre post retention. J Dent. 2008 Apr;36(4):235-

42. D'arcangelo C, Zazzeroni S, D'Amario M, Vadini M, 
De Angelis F, Trubiani O, et al. Bond strengths of three types of fibre-reinforced post systems in various regions of root canals. Int

Endod J. 2008 Apr;41(4):322-8.

43. Kececi AD, Kaya BU, Adanir N. Micro push-out bond strengths of four fiber-reinforced composite post systems and 2 luting materials. Oral Surg, Oral Med, Oral Pathol, Oral Radiol, Endod. 2008 Jan;105(1):121-8.

44. Cencer M, Liu Y, Winter A, Murley M, Meng H, Lee BP. Effect of $\mathrm{pH}$ on the rate of curing and bioadhesive properties of dopamine functionalized poly (ethylene glycol) hydrogels. Biomacromolecules. $2014 \mathrm{Jul} ; 15(8): 2861-9$.

45. Franco EB, Lopes LG, D'alpino PH, Pereira JC. Influence of $\mathrm{pH}$ of different adhesive systems on the polymerization of a chemically cured composite resin. Brazilian Dent J. 2005 Aug;16(2):107-11.

46. Tay FR, Pashley DH. Aggressiveness of contemporary self-etching systems: I: Depth of penetration beyond dentin smear layers. Dent Mater. 2001 Jul;17(4):296-308.

47. da Rosa WL, Piva E, da Silva AF. Bond strength of universal adhesives: A systematic review and meta-analysis. J Dent. 2015 Jul;43(7):765-76.

\section{Cite this paper as}

Azam Valian, Mahsa Maghsoudlou, Mohammad sajjad Roudbari. Push-out bond strength of glass fiber posts with two universal adhesives in endodontically-treated teeth. J Res Dent Maxillofac Sci.2021; $6(3): 8-17$. 